Focused on the "Portuguese contributions for Structural Integrity"

\title{
Effect of machining parameters on the mechanical properties of high dosage short-carbon- fiber reinforced composites
}

\author{
S. E. Oliveira, J.A.M. Ferreira, J. da Silva \\ CEMMPRE, University of Coimbra, Department of Mechanical Engineering, Portugal \\ uc2014184149.seo@outlook.com, bttp://orcid.org/0000-0002-2749-2717 \\ martins.ferreira@dem.uc.pt,http://orcid.org/0000-0002-0295-1841 \\ joel.jesus@uc.pt, bttp://orcid.org/0000-0002-7133-2331 \\ C. Capela \\ Instituto Politécnico de Leiria, ESTG, Department of Mechanical Engineering, Portugal \\ ccapela@ipleiria.pt, bttp://orcid.org/0000-0003-3334-4945
}

\begin{abstract}
The machinability of polymer matrix composites with fibers strongly depends on the type of fiber and dosage in question, having a high influence on the selection of tools and cutting parameters. The cutting temperature depends of rotation speed and the feed cutting tools and is significantly influencing on the quality of the machined surfaces and tool life. This paper presents the results of a current study concerning the effect of the rotation-cutting speed on the cutting temperature, roughness and tensile strength of short carbon fiber reinforced epoxy composites, potentially used in automotive and aeronautic industries. Composite plates were manufactured by compression molding, using short carbon fibers with $0.5 \mathrm{~mm}$ and $6 \mathrm{~mm}$ length. The increasing of the rotation-cutting speed increases significantly the temperature generated in the tool and slightly increases surface roughness. Tensile strength and Young's modulus are little sensitive to drilling speed. However, above $3000 \mathrm{rpm}$ it was observed significant loss of stiffness, associated with the developed temperature in the machining process.
\end{abstract}

KEYwORDS. Mechanical properties; Short fiber composites; Machinability of composites.

\section{OPEN ACCESS}

Citation: Oliveira, S. E., Ferreira, J.A.M., Capela, C., da Silva, J., Effect of machining parameters on the mechanical properties of high dosage short -carbon- fiber reinforced composites, Frattura ed Integrità Strutturale, 48 (2019) 249-256.

Received: 14.09 .2018

Accepted: 24.10 .2018

Published: 01.01.2019

Copyright: (C) 2019 This is an open access article under the terms of the CC-BY 4.0, which permits unrestricted use, distribution, and reproduction in any medium, provided the original author and source are credited.

\section{INTRODUCTION}

$\mathrm{P}$

olymer Matrix Composites are widely used in the manufacture of components for engineering applications [1,2]. In particular, short-fiber Reinforcement Polymer (SFRP) composites are easy to manufacture, have low production costs and good mechanical properties. In general, the addition of short fibers in a polymer matrix aims to obtain 
high performance composites, with the increase of the fiber fraction leading to an increase in modulus and strength of the processed material [3]. However, for a high dosage of reinforcing the homogeneous distribution of the fiber becomes very difficult and the porosity drastically increases, which justifies more detailed studies of this subject.

Machining of fiber-reinforced composites differs significantly in many aspects from the machining of conventional metals and their alloys. In the machining of fiber-reinforced composites the behavior of the material is not only inhomogeneous but it also depends on diverse fiber and matrix properties, fiber orientation, and the relative volume of matrix and fibers [4]. The cutting tool alternately cuts the matrix and the fibers which machining response may be entirely different [4]. In the manufacture of engineering components from composite material, it is sometimes necessary to perform drilling and milling operations. In the case of manufacturing components in a composite material with short fibers, milling operations may be performed to obtain the desired a local geometry of the components. The machinability of polymer matrix composites with fibers strongly depends on the type of fiber and composite dosage and their mechanical and physical (for instance, thermal) properties. However, the type of fiber used in processing of these materials has a major influence on the selection of tools and cutting parameters [5].

The cutting temperature is also a factor that has a significant influence on the quality of the machined surfaces and tool life. In turn, temperature around cutting point and the final surface roughness depend on rotation and feed cutting tools. During the milling of short-fibber-carbon-reinforced composites (SCFC), the temperature on cutting point can cause damage or degradation to the composite's surface.

The surface roughness of the machined area greatly influences the mechanical performance of the dimensional precision and manufacturing costs [5]. Therefore, surface roughness and degradation of the composite's surface require study to ensure the use of an industrial process. This is the first step to study machinability involving a specific composite.

Milling in composite materials is a rather complex task due to its heterogeneity and the emergence of some problems such as surface delamination appearing during the machining process, associated with the characteristics of the material and cutting parameters. Milling is the machining operation most frequently used in the manufacture of fiber-reinforced plastic parts, as a corrective operation to produce well-defined and high-quality surfaces that often require the removal of excess material to control tolerances. Therefore, the ability to predict the cutting forces is essential to select process parameters which are necessary for an optimal machining. Mechanical performance of SCFC depends mainly on the capacity to obtain good fiber dispersion, usually evaluated by nondestructive methods such as ultrasonic $\mathrm{C}$ scanning and acoustic emission $[6,7]$.

This paper studied the effect of cutting conditions during milling machining on roughness, cutting temperature and mechanical properties, with the purpose of contributing for a better understanding of the interdependence of these parameters, especially in the case of composites with high dosage.

\section{MATERIALS AND SAMPLES}

$\mathrm{F}$ or this investigation two composite batches were manufactured:

a) a $6 \mathrm{~mm}$ length fiber, and using Biresin ${ }^{\circledR}$ CR120 as matrix, formulated by bisphenol A - epichlorhydrin epoxy resin 1,4 - bis (2,3-epoxypropoxy) butane, combined with the hardener $\mathrm{CH} 120-3$, with $40 \%$ (in volume fraction) of carbon fibers.

b) $0.5 \mathrm{~mm} \pm 0.15$ in length and $7 \mu \mathrm{m} \pm 2 \varnothing$ monofilaments, using Biresin ${ }^{\circledR}$ CR83 matrix reinforced with $17.5 \%$ (in volume fraction) of carbon fibers.

Resins were supplied by Sika, Stuttgart, Germany, while the company Sigrafil, SGL Group, Germany, supplied the fibers. Composite plates were manufactured by manual molding process, pressing the mold in a servo mechanical machine, Mazzola W15. The compression was applied such as it is shown schematically in Fig. 1, which also shows the mold and the positioning of the pressure transducer used to monitor inside pressure during the cure process. The desired amount of fibers previously subjected to the fiber separation treatment was added to the resin. Then, the materials were mixed and placed in the mold cavity. Afterwards, the mold was closed and placed in the mechanical compression load at $7600 \mathrm{daN}$, with corresponding pressure of about 50.7 bar. The processed plates were then subjected to cure and post cure processes. Fig. 2a) shows the mold design and a final composite plate. From this plate, test specimens were later machined according to the scheme and dimensions indicated in Fig. 2b).

Composite plates were subjected to a cure process done at room temperature for 20 hours in the mold, and a post cure was carried out at $70^{\circ} \mathrm{C}$ for 12 hours. The pressure during the curing process was monitored by the pressure transducer shown in Fig. 1. As shown in Fig. 2c) the pressure remains nearly constant for the entire duration of the cure process. 
The specimens were machined according to the geometry and dimensions indicated in Fig. 2b) from the plates with dimensions 150x100x5 mm^3 using a Computer Numerical Control (CNC) milling machine, Hass Mikron VCE 500 and a Sandvik carbide tool with a diameter of $20 \mathrm{~mm}$, part number SANDVIK R390-11T308E-NL H13A. The machining parameters used are indicated in Tab. 1. Fig. 3 presents the most relevant details of track strategies for the plate machining to increasing cutting speed.

\begin{tabular}{cccc}
\hline Spindle speed, $(\mathrm{rpm})$ & Cutting speed, $(\mathrm{mm} / \mathrm{min})$ & Axial increment, $(\mathrm{mm})$ & Inclination angle axis, $\left({ }^{\circ}\right)$ \\
750 & 50 & 1.0 & 0 \\
1500 & 100 & 1.0 & 0 \\
2250 & 150 & 1.0 & 0 \\
3000 & 200 & 1.0 & 0 \\
4500 & 300 & 1.0 & 0 \\
\hline
\end{tabular}

Table 1: Cutting parameters used in the machining of composite plates.

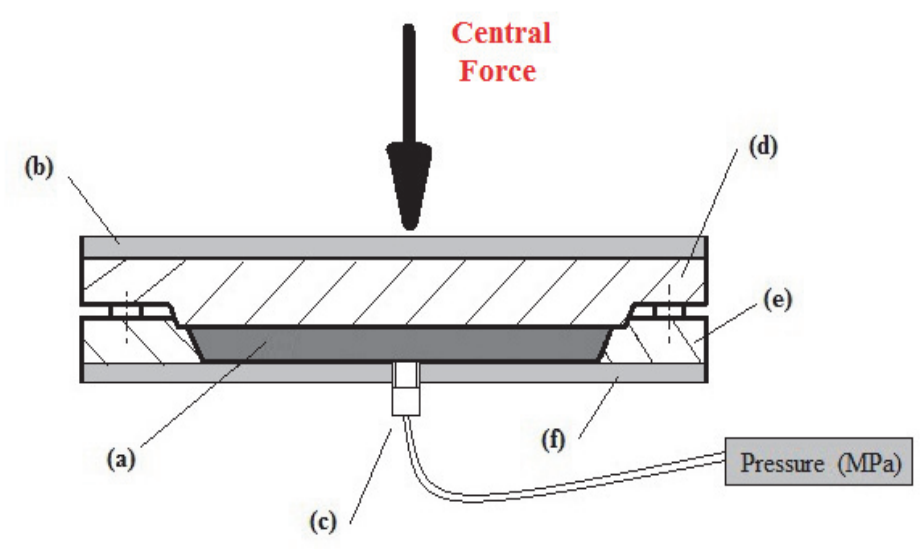

Figure 1: Scheme of molding apparatus: (a) Composite plate. (b) Rubber base. (c) Pressure transducer. (d) Steel upper die part. (e) Steel lower die part. (f) Aluminum base.

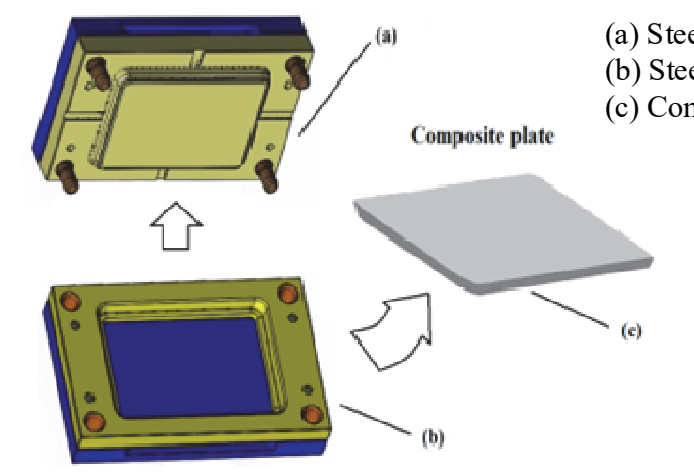

a)
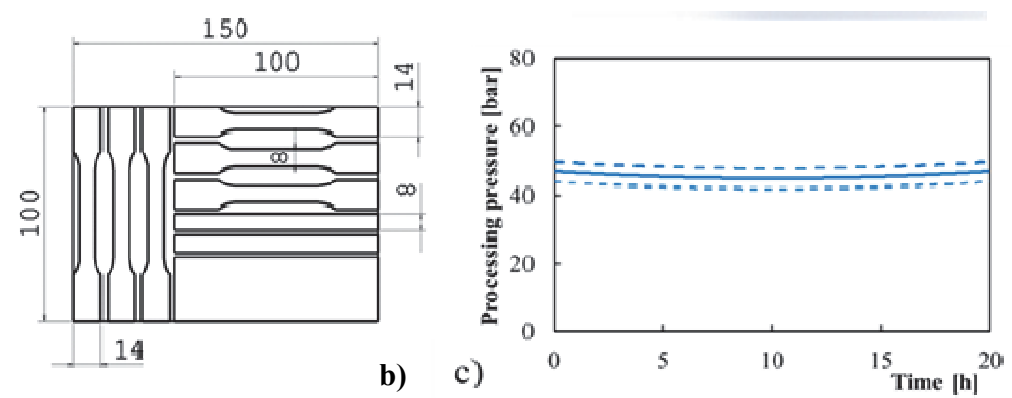

Figure 2: a) Molding cavity; b) Final specimen dimensions (units in $\mathrm{mm}$ ); c) Curing pressure. 


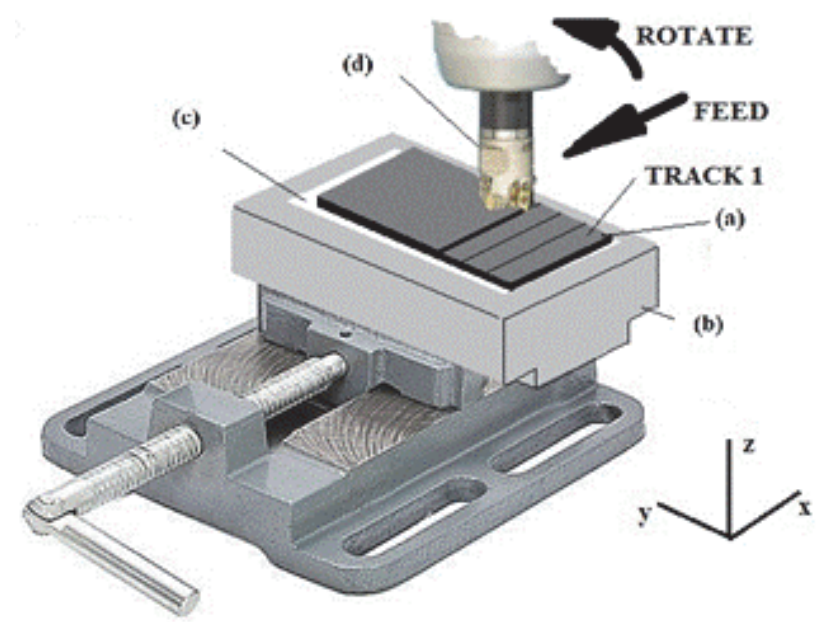

Figure 3: Schematic view of the plate machining: (a) Composite plate; (b) Fittings; (c) Double Adhesive Band; (d) Plane-end mill set.

\section{EXPERIMENTAL TESTING}

emperature profile is important to determine the limits for cutting speed. During the drilling process the temperature around the cutting tool was monitored using a Thermographic camera, Testo 875, as shown in exemplary Fig. 4.

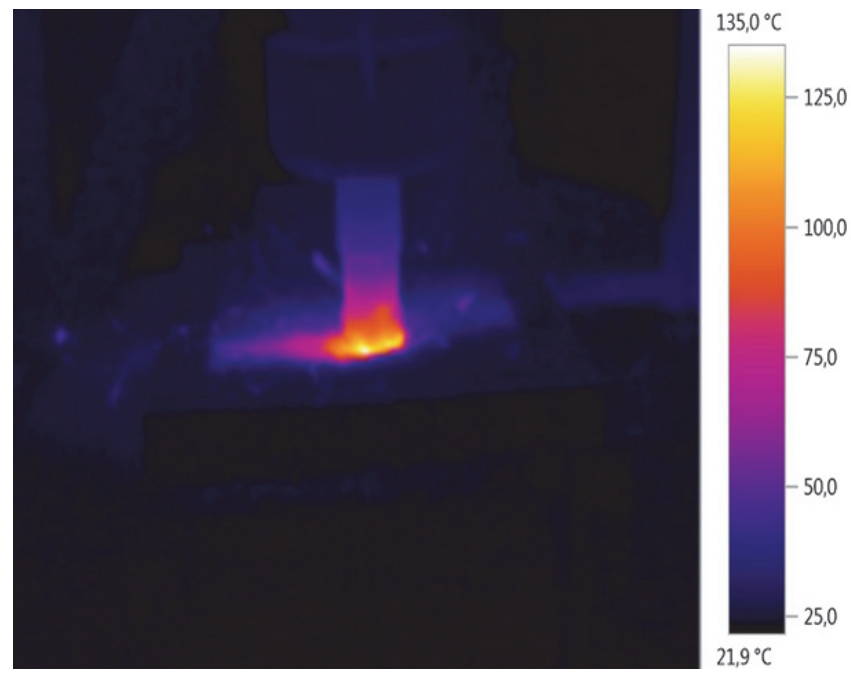

Figure 4: Surface drilling and temperature measurement. Sample manufactured with fiber length $6 \mathrm{~mm}$ and spindle speed $4500 \mathrm{rpm}$.

Surface roughness was quantified using the standardizing parameter $\mathrm{R} z$, which is the arithmetic average of five distances values between the highest peak and lowest valley in each sampling length measures at $15 \mathrm{~mm}$. Roughness measurements were carried out using the equipment Surface Measuring Instrument Mitutoyo Surftest SJ-500.

Tensile tests for the characterization of the mechanical properties, tensile strength and Young's modulus were performed using a Machining INSTRON model 4206, monitoring the load and the displacement through an axial extensometer.

Fiber dispersion into composite was checked using optical equipment [8], the scanning electronic microscopy (SEM) Philips XL30. After carrying out tensile tests, the fracture surfaces in some specimens were gold sputtered and then observed in SEM to understand the fiber adhesion failure mechanisms. Fig. 5 shows a SEM low magnification characteristic micrograph of the fracture of an external face of a specimen with $0.5 \mathrm{~mm}$ length fiber, in which a reasonable dispersion was observed, only with partial separation of the fibers. This kind of microscopic structure was observed in other specimens and cannot be classified as an isometric structure. 


\section{RESULTS AND DISCUSSION}

$\mathrm{S}$ urface roughness was analyzed to verify the adequacy of the machined processing under development. Fig. 6 shows the results obtained for both material batches: length fiber $0.5 \mathrm{~mm}$ and $6 \mathrm{~mm}$, presenting the average values and the dispersion range of the experimental tests. The analysis of the figure shows that the experimental results are in good agreement with the usual values in the manufacturing industry, particularly to metallic materials. These results indicate that the parameter $\mathrm{Rz}$ increases slightly with the drilling speed, in spite of the natural dispersion of the results. Composites with lower fiber length and content exhibit much higher roughness $\mathrm{Rz}$, probably a consequence of the lower glass transition temperature, $\mathrm{Tg}$, of the polymer resin, and consequently in this case it is easier for the temperature on the surface of the tool to reach a value close to or greater than $\mathrm{Tg}$ during the cutting operation. The analysis of the data indicated that the speed cutting up to $2250 \mathrm{rpm}$ and feed $150 \mathrm{~mm}$ per minute presents smaller values of surface roughness.

The temperature on the surface of the carbide tool during the cutting of the SCFC plates was measured with an infrared thermograph camera, as shown in Fig. 4. The values of the maximum observed temperature in the cutting tool during face machining are plotted against the rotation speed for both composites in Fig. 7. In both cases, a significant increase of the temperature with the increase of cutting speed was observed. The temperature profile reveals that in some cases (above $3000 \mathrm{rpm}$ ) its values reach the glass transition temperature, $\mathrm{Tg}$, of the polymer matrices. For the $6 \mathrm{~mm}$ fibers composites the $\operatorname{Tg}$ of the resin $\left(113^{\circ} \mathrm{C}[9]\right)$, while for Biresin ${ }^{\circledR} \mathrm{CR} 83$ resin, $\operatorname{Tg} 84^{\circ} \mathrm{C}$, according the manufacturer.

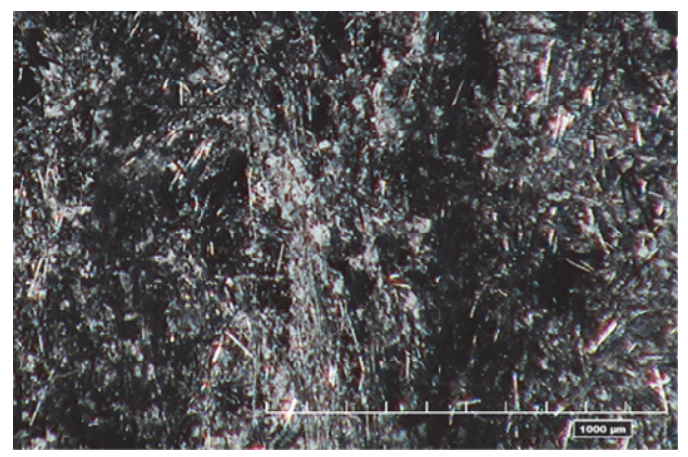

Figure 5: SEM low magnification characteristic micrograph of the fracture surface.

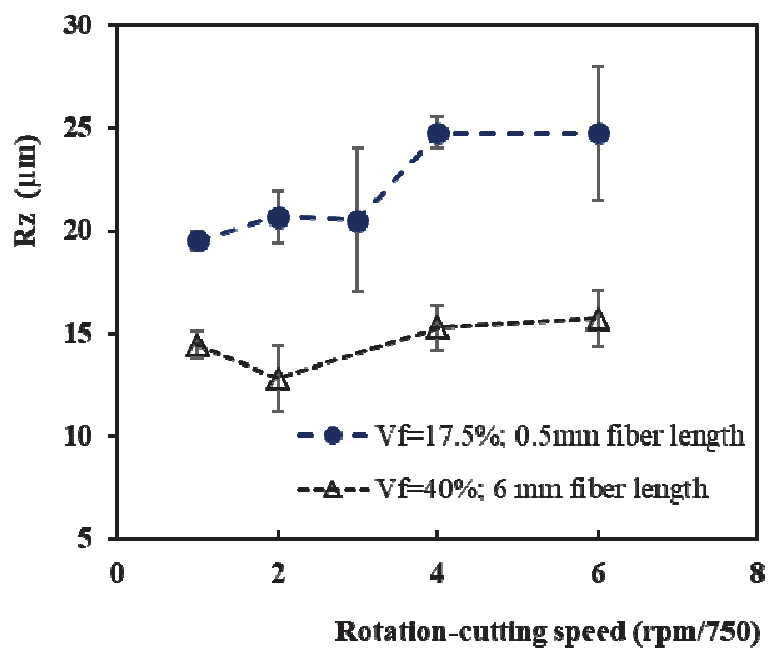

Figure 6: Surface roughness, Rz, against drilling speed.

The results of the tensile tests are summarized in Figs. 8 and 9, which present the tensile strength and the Young's modulus, respectively, against drilling speed. Tensile strength is the axial stress for the load peak of the load versus 
displacement curves. The stiffness modulus was calculated using the linear elastic Hooke's law in the linear region of load versus displacement plot. The collected values presented a correlation coefficient at least 0.99. Contrary to the reported on scientific literature [3], a decreasing of the tensile strength with the increasing of both fiber content and length was observed. These results are justified by the poor fiber distribution, poor fiber/matrix adhesion and increasing porosity for higher fiber dosage composites. On the other side, and despite high dispersion of the results, rotation-cutting speed seems to play a reduced effect on composite tensile strength, for both materials.

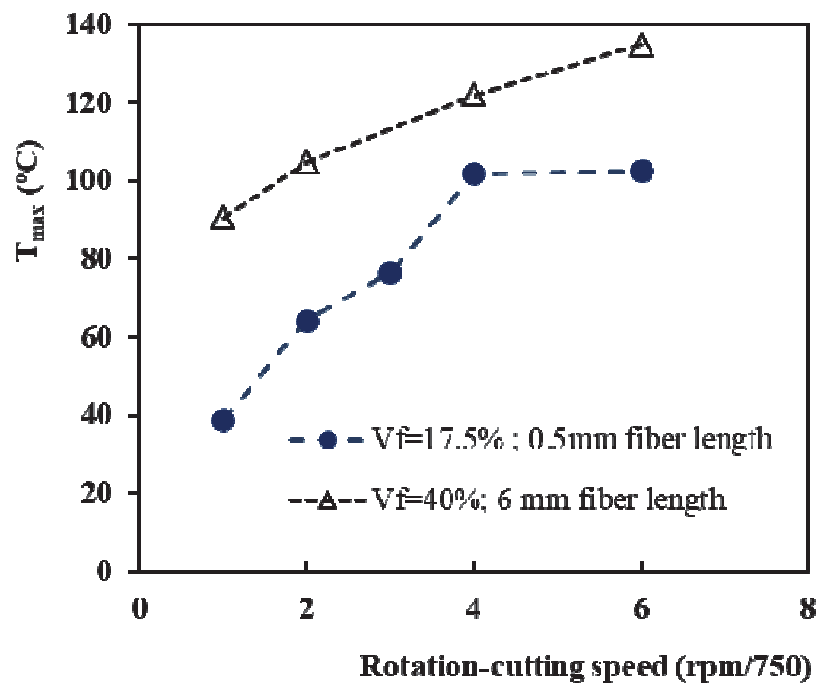

Figure 7: Maximum temperature around carbon tool against drilling speed.

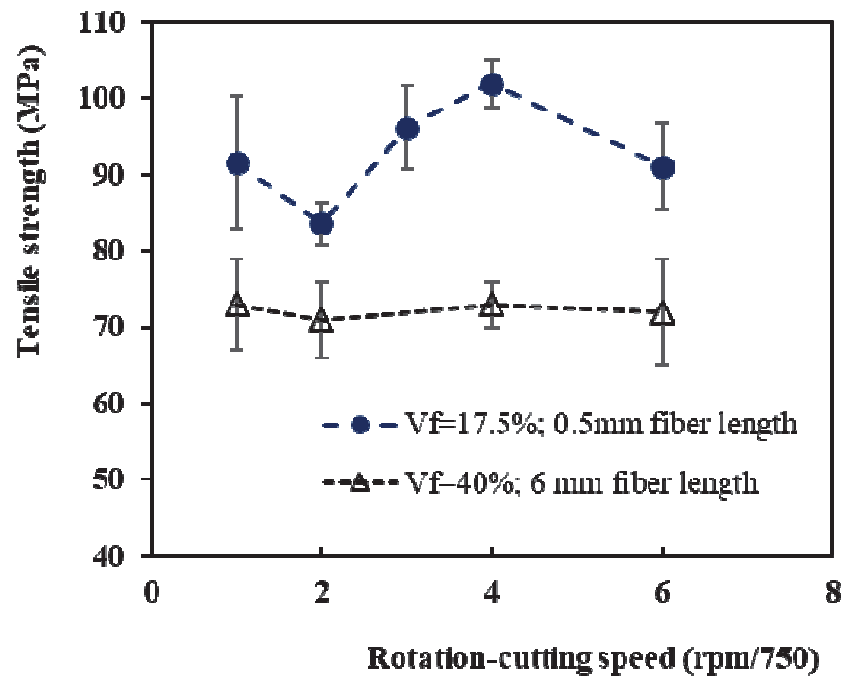

Figure 8: Tensile strength against rotation-cutting speed.

The analysis of the stiffness modulus, shown in Fig. 9, indicates that in this case the results are in accordance with the reported on literature [3], as it was observed an increasing of the stiffness with the increasing of both fiber content and length. The results mean that fibber distribution and porosity play a less significant role on composite stiffness than in tensile strength. The analysis of the figure also shows significant dispersion (with standard deviations from 0.25 to 2.65 $\mathrm{GPa}$ ), but an important aspect must be stated for both materials: above $3000 \mathrm{rpm}$ there is a significant loss of stiffness. This loss of rigidity may be associated with the temperature developed in the machining process and consequent degradation of the matrix. 
Failure surface of some samples was observed in the Scanning Electron Microscope. Fig. 10 shows a SEM micrograph feature for $6 \mathrm{~mm}$ length fiber composites fiber composites, which reveals a fair adhesion between resin matrix and fibers. It can also be observed some lack of polymers between the fiber and the fiber pullout, as reported in literature for high dosage composites $[8,10]$. On the other hand, as shown in Fig. 5, the composites with $0.5 \mathrm{~mm}$ fiber length shows much better fiber dispersion and lower resin lacks.

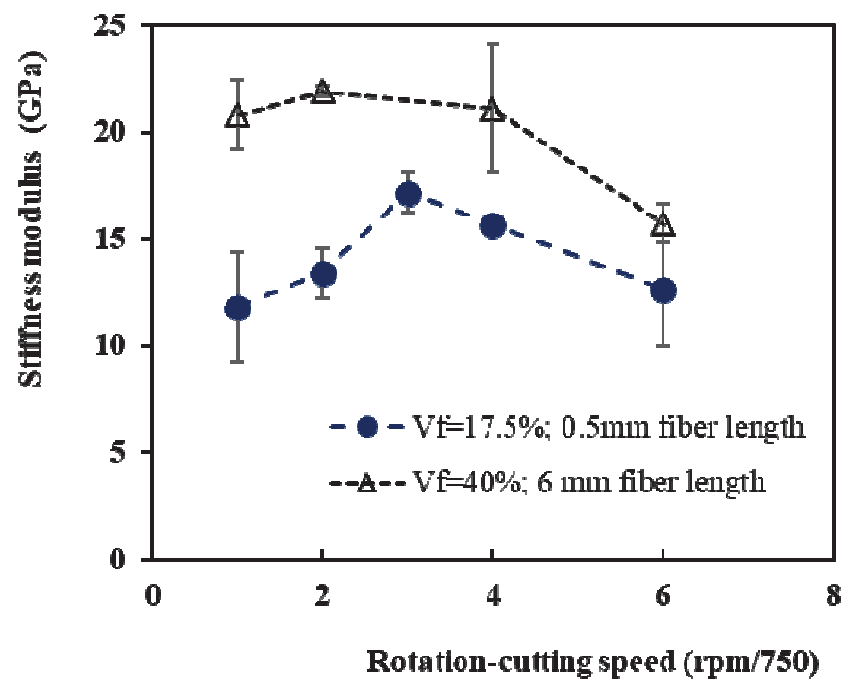

Figure 9: Stiffness modulus against drilling speed.

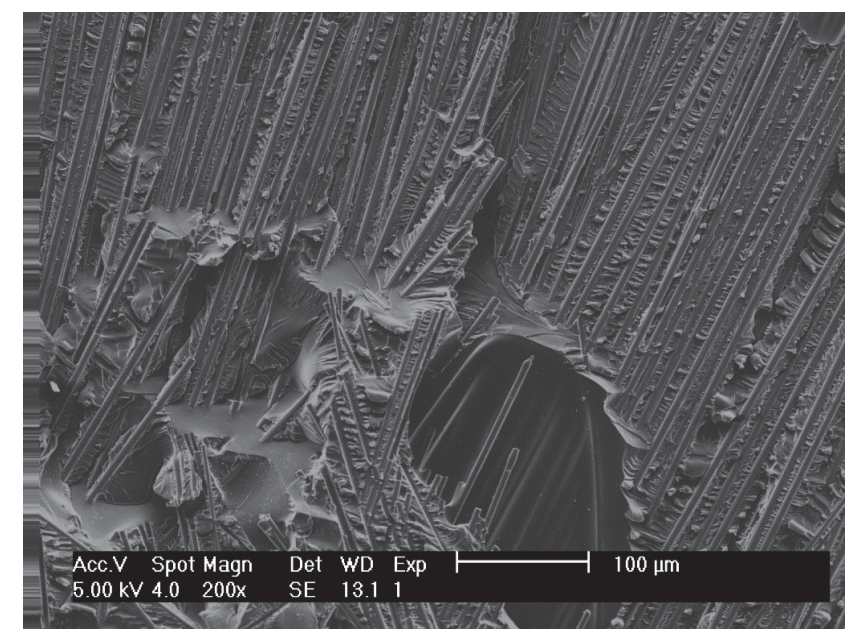

Figure 10: SEM observations of fracture surfaces for $6 \mathrm{~mm}$ fibers composites.

\section{CONCLUSIONS}

his work studied the effect of rotation-cutting speed on the cutting temperature, roughness and tensile properties of two epoxy based composites reinforced with $17.5 \%$ and $40 \%$ in volume fraction short carbon fiber. The main conclusions drawn can be summarized as follows:

The increasing of rotation-cutting speed significantly increases the temperature generated in the tool reaching the glass transition temperature, $\mathrm{Tg}$ of the polymer matrices.

The surface roughness $(\mathrm{Rz})$ only slightly increases with the drilling speed. 
Mechanical properties such as tensile strength and Young's modulus are not very sensitive to drilling speed. Nonetheless, the high dispersion of the results for rotation-cutting speed seems to play a reduced effect on composite tensile strength and stiffness for both materials. In any case, above $3000 \mathrm{rpm}$ a significant loss of stiffness was observed, which may be associated with the temperature developed in the machining process, which reached values above the glass transition temperature $(\mathrm{Tg})$ of the resin.

Tensile stiffness increases significantly with the simultaneous increasing in the fiber content and length. In fact, tensile strength decreases with the increasing of the fiber content and length, in consequence of the poor fiber distribution and very high porosity for the too high fiber dosage composites.

\section{ACKNOWLEDGMENTS}

7 his research is sponsored by FEDER funds through the program COMPETE - Programa Operacional Factores de Competitividade - and by national funds through FCT - Fundação para a Ciência e a Tecnologia -, under the project PEst-C/EME/UI0285/2013. The authors thank the part of support to this investigation by the Brazilian agency CNPq, Conselho Nacional de Desenvolvimento Ciêntifico e Tecnológico, CsF.

\section{REFERENCES}

[1] Shahrajabiana, H., Hadia, M. and Farahnakian, M. (2012). Experimental Investigation of Machining Parameters on Machinability of Carbon Fiber/Epoxy Composites, Int. J. of Eng. and Innov. Tech. (IJEIT), 2 (3), pp. 30-32.

[2] Agarwal, G., Patnaik, A. and Sharma, R. K. (2014). Mechanical and thermo-mechanical properties of bi-directional and short carbon fiber reinforced epoxy composites. J. of Eng. Sci. and Tech., School of Engineering, 9(5), pp. 590 604.

[3] Fu, S. Y., Lauke, B, Mäder, E., Yue, C. Y. and Hu, X. (2000). Tensile properties of short-glass-fiber- and short-fibbercarbon-reinforced polypropylene composites, Composites: Part A 31, pp.1117-1125.

DOI: 10.1016/S1359-835X(00)00068-3.

[4] Komanduri, R. (1997). Machining of fiber-reinforced Composite. Machining Science and Technology, 1 (1), pp. 113152. DOI: $10.1080 / 10940349708945641$.

[5] Davim, J. P. and Reis, P. (2004). Damage and dimensional precision on milling carbon fiber-reinforced plastics using design experiments. J. of Mat. Proc. Tech. 160, pp. 160-167. DOI: 10.1016/j.jmatprotec.2004.06.003.

[6] Park J.M., Lee S.I., Kim K.W. and Yoon D.J. (2001). Interfacial aspects of electrodeposited conductive fibers/epoxy composites using electro-micromechanical technique and nondestructive evaluation. J Colloid Interface Sci., 237, pp. 80-90. DOI: $10.1006 /$ jcis.2001.7426.

[7] Xu X., Zhou Z., Hei Y., Zhang B., Bao J. and Chen X. (2014). Improving compression-afterimpact performance of carbon-fiber composites by CNTs/thermoplastic hybrid film interlayer. Compos Sci Technol, 95, pp. 75-81.

[8] Habib, S. and Okada, A. (2016), Influence of electrical discharge machining parameters on cutting parameters of carbon fiber-reinforced plastic. Mach. Sc. and Tech., 20(1), pp. 99-114. DOI: 10.1080/10910344.2015.1133914.

[9] Yashiro, T., Ogawa, T. and Sasahara, H. (2013). Temperature measurement of cutting tool and machined surface layer in milling of CFRP. Int. J. of Machine Tools \& Manufacture, 70, pp. 63-69. DOI: 10.1016/j.ijmachtools.2013.03.009.

[10] Agarwal, H., Amaranath, A., Jamthe, Y. and Gururaja, S. (2015). An investigation of cutting mechanisms and strain fields during orthogonal cutting in CFRPs. Machining Science and Technology, 19 (3), pp. 416-439.

DOI: 10.1080/10910344.2015.1051539. 